\title{
Oxygen cost of recreational horse-riding in females
}

\begin{tabular}{|r|l|}
\hline Journal: & Journal of Physical Activity \& Health \\
\hline Manuscript ID: & JPAH_2012_0428.R1 \\
\hline Manuscript Type: & Article \\
\hline Keywords: & $\begin{array}{l}\text { exercise, guidelines and recommendations, physical activity assessment, } \\
\text { recreation }\end{array}$ \\
\hline
\end{tabular}

\section{SCHOLARONE ${ }^{\text {th }}$}

Manuscripts 
1

2

3

4

5

5

7

7 10

\section{Oxygen cost of recreational horse-riding in females}

2

3 Running head: Oxygen cost of recreational horse-riding

4 Manuscript Type: Original Research

5 Keywords: Exercise intensity, energy expenditure, physical activity

6 Abstract Word Count: 197

7 Manuscript Word Count: 2,807

8 Date of manuscript submission: $21^{\text {st }}$ October 2012

9 Date of submission of revised manuscript: $9^{\text {th }}$ September 2013 


\section{Abstract}

12 Background: The purpose of this study was to characterize the physiological demands of a riding 13 session comprising different types of recreational horse riding in females. Methods: Sixteen female 14 recreational riders (aged 17-54 years) completed an incremental cycle ergometer exercise test to 15 determine peak oxygen consumption $\left(\mathrm{VO}_{2 \text { peak }}\right)$ and a 45 minute riding session based upon a British 16 Horse Society Stage 2 riding lesson (including walking, trotting, cantering and work without stirrups). 17 Oxygen consumption $\left(\mathrm{VO}_{2}\right)$, from which metabolic equivalent (MET) and energy expenditure values 18 were derived, was measured throughout. Results: The mean $\mathrm{VO}_{2}$ requirement for trotting/cantering $19\left(18.4 \pm 5.1 \mathrm{ml} \cdot \mathrm{kg}^{-1} \cdot \mathrm{min}^{-1} ; 52 \pm 12 \% \mathrm{VO}_{2 \text { peak }} ; 5.3 \pm 1.1 \mathrm{METs}\right)$ was similar to walking/trotting $(17.4 \pm$ $\left.205.1 \mathrm{ml} \cdot \mathrm{kg}^{-1} \cdot \mathrm{min}^{-1} ; 48 \pm 13 \% \mathrm{VO}_{2 \text { peak }} ; 5.0 \pm 1.5 \mathrm{METs}\right)$ and significantly higher than for work without 21 stirrups $\left(14.2 \pm 2.9 \mathrm{ml} \cdot \mathrm{kg}^{-1} \cdot \mathrm{min}^{-1} ; 41 \pm 12 \% \mathrm{VO}_{2 \text { peak }} ; 4.2 \pm 0.8 \mathrm{METs}\right)(P=0.001)$. Conclusions: The 22 oxygen cost of different activities typically performed in a recreational horse riding session meets the 23 criteria for moderate intensity exercise (3-6 METs) in females, and trotting combined with cantering 24 imposes the highest metabolic demand. Regular riding could contribute to the achievement of the 25 public health recommendations for physical activity in this population. 


3

4

\section{Introduction}

Physical activity guidelines for health promotion recommend that all healthy adults aged 18-65 years should aim to take part in at least 150 minutes of moderate intensity aerobic activity each week, or at least 75 minutes of vigorous-intensity aerobic activity each week, or equivalent combinations of moderate and vigorous intensity aerobic activities. ${ }^{1-3}$ Exercise intensity may be expressed as an absolute measure, for example metabolic equivalents (METs) where one MET is equivalent to oxygen consumption $\left(\mathrm{VO}_{2}\right)$ at rest $\left(3.5 \mathrm{ml} \cdot \mathrm{O}_{2} \cdot \mathrm{kg}^{-1} \cdot \mathrm{min}^{-1}\right)$, or as a relative measure such as percentage of maximal oxygen consumption $\left(\mathrm{VO}_{2 \max }\right)$. A perceptual scale such as Borg's Rating of Perceived Exertion (RPE) ${ }^{4}$ may also be used as a subjective measure of intensity. In terms of energy expenditure, one MET is also expressed as a standard resting metabolic rate of $1.0 \mathrm{kcal}(4.184 \mathrm{~kJ}) \cdot \mathrm{kg}^{-1} \cdot \mathrm{h}^{-1} .5$ Moderate intensity physical activity is categorized as 3-6 METS, $40-60 \% \mathrm{VO}_{2 \max }$ or an RPE of 12 $13 .^{2,6}$ Vigorous intensity exercise is 6-9 METs, $60-85 \% \mathrm{VO}_{2 \max }$ or RPE of 14-16.

41 In addition to popular activities such as walking and cycling, a wide variety of leisure, household and 42 occupational activities performed at a moderate intensity may contribute to individuals achieving the recommended amount of physical activity. However, some popular leisure activities, for example golf and some Nintendo Wii sports, may not be of a sufficient intensity to offer health benefits. ${ }^{78}$ Horse riding as a leisure pursuit offers an opportunity to increase physical activity. It has been identified as one of several "green exercises" (activities involving contact with the natural environment and green space) that promote good health by improving self-esteem and mood. ${ }^{9}$ Psychotherapeutic benefits from horse riding therapy have also been observed. ${ }^{10}$ In the UK, there are more than 430 riding clubs affiliated to the British Horse Society, which has over 34,000 members. In a survey of 1,248 recreational horse riders, $68 \%$ respondents said that they exercised at a moderate intensity for 30 
Oxygen cost of recreational horse-riding

51 minutes at least 3 times per week by horse riding and/or associated activities (e.g. grooming and 52 mucking-out). ${ }^{11}$ Over a third indicated that horse riding was the only form of physical activity that they 53 had participated in during the preceding 4 weeks. Ninety three percent of respondents were female, and 54 half of these were aged 45 or above, a population group for whom physical activity levels are generally 55 low. ${ }^{12}$ Similarly a major national survey shows that the gender ( $90 \%$ female) and age profile (a large 56 proportion of over 45 year olds) of equestrianism is not matched by any other sport in the UK. ${ }^{13}$

There is at present limited and, indeed, conflicting empirical evidence to show if the physiological demands of recreational horse riding are likely to confer health benefits. The Compendium of Physical Activities $^{5,14}$ includes MET intensity levels for specific physical activities and is used to identify examples of moderate and vigorous intensity activities and to evaluate the contributions of various types of physical activity to daily energy expenditure. The value for general horseback riding is given as 5.5 METs, based on data averaged from walking (3.8 METs), trotting (5.8 METs) and cantering or galloping (7.3 METs). These values may not represent the physiological demand of recreational horseriding in females as they are derived from indirect calorimetry measurements taken several decades ago in a small number of young male soldiers ${ }^{15}$, Guatemalan male peasants performing agricultural activities $^{16}$, and more recently in five experienced competitive riders of whom only three were female. $^{17}$

Technical innovation in the development of portable gas analysis systems has enabled the valid measurement of expired air and energy expenditure in the field during different physical activities. ${ }^{18-20}$ In addition to the aforementioned study ${ }^{17}$, two other studies have assessed the physiological demands of horse riding. In sixteen female equestrian athletes participating in a simulated one day event competition, $\mathrm{VO}_{2}$ was equivalent to 6 METs $\left(20.4 \pm 4 \mathrm{ml} \cdot \mathrm{kg}^{-1} \cdot \mathrm{min}^{-1}\right)$ during dressage, 8 METS $(28.1 \pm$ 
$\left.754.2 \mathrm{ml} \cdot \mathrm{kg}^{-1} \cdot \mathrm{min}^{-1}\right)$ during show jumping and 9 METS $\left(31.2 \pm 6.6 \mathrm{ml} . \mathrm{kg}^{-1} \cdot \mathrm{min}^{-1}\right)$ during cross country. ${ }^{21}$

76 There was variability in the oxygen cost between riders performing in the same simulated competition 77 but riding different horses. An earlier study of thirteen experienced and three elite horse riders reported 78 that the intensity of walking, trotting and cantering ranged from $40-80 \% \mathrm{VO}_{2 \mathrm{max}}$, with walking and 79 trotting fitting with the classification of moderate intensity, and cantering vigorous intensity $(>60 \%$ $80 \mathrm{VO}_{2 \max . .}{ }^{22}$

81

82 The above studies provide information about competitive equestrianism, but the physiological demands 83 of modern-day recreational riding and its potential contribution to health-related energy expenditure is 84 not well-documented. A three month training programme of moderate intensity simulated mechanical 85 horse riding improved metabolic health in middle-aged and elderly individuals with type II diabetes. ${ }^{23}$, 8624 However, in younger healthy females with higher baseline fitness a 14 week horse riding training 87 programme did not provide an adequate stimulus to improve health and fitness. ${ }^{25}$ 88

89 The purpose of this study was to characterize the physiological demands of different types of horse 90 riding in females during a recreational horse riding session. A secondary aim was to ascertain whether 91 the intensity of the different riding activities was sufficient to be classed as at least 'moderate' ( $\geq 3$ 92 METS) and could therefore contribute to the current physical activity for health recommendations. 
98 Twenty mixed-ability female recreational horse riders aged between 17 and 54 years were recruited 99 from the population of students and staff on University-based Equine Studies-related courses. The 100 participants were limited to volunteers with no known cardiovascular/pulmonary disease, pregnancy, 9101 metabolic disorders or contraindications to exercise as determined by a medical questionnaire. Nine 10

participants were categorised as novice riders ( $<2$ years' experience) and seven as experienced riders ( $>2$ years' experience). Eight individuals were categorised as "very active" $\left(>6\right.$ hr.week ${ }^{-1}$ activity $\geq$ moderate intensity, seven as "active" (3-6 hr.week ${ }^{-1}$ activity $\geq$ moderate intensity) and one as "moderately active" (1-3 hr.week ${ }^{-1}$ activity $\geq$ moderate intensity). Participation in recreational horse riding (including similar activities to those described below under "Horse Riding Session") was

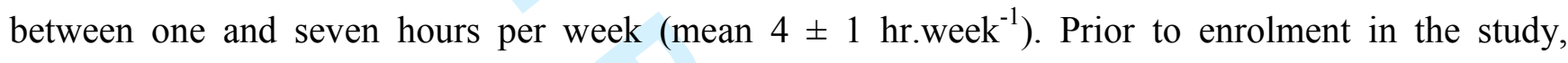
participants were provided with verbal and written explanations of the purpose, procedures, possible benefits, risks and discomforts associated with participation. Following this full explanation, written informed consent was obtained, in addition to written parental consent for volunteers aged under 18 years. The study was granted institutional ethical approval and was conducted in accordance with the Declaration of Helsinki.

Laboratory procedures took place during one visit to the University Human Performance Laboratory, followed 1-2 weeks later by a horse riding session in an equestrian centre.

\section{Anthropometry}

Participants visited the Laboratory having refrained from eating for at least two hours, and from heavy exercise and alcohol consumption for 24 hours. Height $(\mathrm{m})$ and weight $(\mathrm{kg})$ were measured using calibrated scales and a stadiometer (Detecto, USA). Body mass index (BMI) was calculated by 
dividing body mass by the square of the subjects' height. Skinfold thickness was measured to the nearest $0.2 \mathrm{~mm}$ at iliac crest, subscapular, triceps, and biceps skinfold sites and used to calculate body density. ${ }^{26}$ Percentage body fat was estimated from body density values using the Siri equation. ${ }^{27}$

\section{Laboratory cycle ergometer test}

Participants performed a maximal incremental cycling test on an SRM cycle ergometer (Schroberer Rad Messtechnik, Weldorf, Germany). Following a 5 minute warm-up at an intensity of 50 Watts (W), starting power was set to $90 \mathrm{~W}$ or $100 \mathrm{~W}$ with increments of $10 \mathrm{~W} \cdot \mathrm{min}^{-1}$ or $13 \mathrm{~W} \cdot \mathrm{min}^{-1}$ respectively for older/less active or younger/more active participants respectively. ${ }^{28}$ All participants were encouraged to continue cycling until volitional exhaustion. Expired air was analysed using a portable indirect calorimetry gas-exchange system (MetaMax ${ }^{\circledR} 3 \mathrm{X}$, Cortex Biophysik, Leipzig, Germany). This consists of a processing unit containing oxygen and carbon dioxide analysers and a battery pack, both worn by participants in a harness on the chest (weight $=1.5 \mathrm{~kg}$ ) and a facemask (Hans Rudolph, Kansas City, USA) containing a turbine flow meter and a sample line connected to the processing unit. The recommended calibration procedure was conducted prior to each laboratory test. Gas sensors were calibrated against known concentration gases, respiratory volumes were calibrated using a 3 L syringe, and ambient air measurements were conducted repeatedly. $\mathrm{VO}_{2}$ was averaged over a 10 second period, and $\mathrm{VO}_{2 \text { peak }}$ was calculated as the highest value from a 30s rolling average during the final stage of the test. $\mathrm{VO}_{2 \text { peak }}$ was also expressed as a percentage of predicted value. ${ }^{29}$

Horse riding session 
Oxygen cost of recreational horse-riding

145

3

4

5

$7 \quad 147$

8

9148

Participants completed a standardised 45 minute horse riding session lead by a qualified instructor at an indoor equestrian centre. The session protocol was based on a British Horse Society Stage 2 riding lesson (Table 1) aimed at intermediate level recreational riders. This followed the "English" rather than "Western" style of riding and included the posting trot, where riders rise and sit in rhythm with the horse's stride. 4 different horses were used. These were selected on the basis of similar $+/-1$ inch in height and similar temperament. All horses were familiar with the environment, and the riders were familiar with riding these horses.

RPE was recorded at 15 minute intervals without disruption to the horse riding session. Expired air was analysed continuously throughout the 45 minute protocol via the same MetaMax ${ }^{\circledR} 3 \mathrm{X}$ portable metabolic measurement system used in the laboratory test, which was calibrated using ambient air prior to every horse riding session. Respiratory gas parameters were collected for each breath and data were averaged over $10 \mathrm{~s}$. Average values were calculated for $\mathrm{VO}_{2}$, carbon dioxide production $\left(\mathrm{VCO}_{2}\right)$, respiratory exchange ratio (RER) and minute ventilation $\left(V_{E}\right)$ and energy expenditure $\left(k c a l \cdot \mathrm{min}^{-1}\right)$ for the 45 minutes session. Average values were also calculated for the walk and trot work (5-15 min), trot and canter work (15-25 min), and work without stirrups (25-35 min) sections of the session.

Data Analysis

Data were analysed using IBM SPSS Statistics for Windows, Version 20. (Armonk, NY: IBM Corp.)

Descriptive data is reported as mean \pm standard deviation. To determine the intensity of the different types of horse riding, $\mathrm{VO}_{2}$ was expressed as METs. $\mathrm{VO}_{2}$ was also calculated as a percentage of individual $\mathrm{VO}_{2 \text { peak }}$ values determined from the laboratory test, and energy expenditure $\left(\mathrm{kcal}^{\mathrm{min}} \mathrm{m}^{-1}\right)$ was estimated from $\mathrm{VO}_{2}$ values using the energy release for $\mathrm{VO}_{2}$ constant of $4.9 \mathrm{kcal}$ per $1 \mathrm{~L} \mathrm{O}_{2}{ }^{30} \mathrm{VO}_{2}$ and 
1

2 3

5

6

7

8

10

11

$12^{173}$

13

14174

15

16

17

18

19

20

21

22

23

24

25

26

27

28

29

30

31

32

33

34

35

36

37

38

39

40

41

42

43

44

45

46

47

48

49

50

51

52

53

54

55

56

57

58

59

60

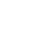

(1)

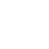

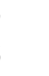

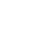

.

4

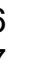

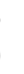
1 54 56

169 intensity were compared for the different riding activities and level of experience using a $3 \times 2$ factorial ANOVA with post hoc Bonferroni comparisons. Pearson's correlational analysis was used to examine the relationship between oxygen cost and age, body mass, \% body fat, riding frequency and fitness.

72 Statistical significance was set at $\mathrm{P} \leq 0.05$.

4 
Oxygen cost of recreational horse-riding

\section{Results}

Twenty participants visited the Laboratory and completed the cycle ergometer test. Four participants did not complete the study as they were unable to attend the riding session. Participant characteristics are presented in Table 2. Test termination was due to volitional exhaustion in all participants. Peak power output was $180 \pm 26 \mathrm{~W}$, peak RPE $19 \pm 1$ and peak RER $1.16 \pm 0.09$. Table 3 presents the data for the different horse-riding activities performed during the session. There was a significant withinsubjects effect in the comparison of oxygen cost between the walk/trot, trot/canter and work without stirrups sections of the riding session $\left(P=0.034\right.$, partial $\eta^{2}=0.265$, observed power $\left.=0.69\right)$. Post hoc tests identified that the "trot/canter" activity was significantly higher than the "without stirrups" activity $(P=0.001)$. Similarly $\% \mathrm{VO}_{2 \text { peak }}$ and METS and energy expenditure values were all significantly higher during "trot/canter" than "without stirrups" $(\mathrm{P}<0.05)$. There was a significant within-subjects effect for RPE between the different riding activities $(\mathrm{P}=0.032)$, but the post hoc follow up tests were not significant. There were no differences in oxygen cost, intensity or RPE between experienced and novice riders. Figure 1 displays mean MET values averaged over each minute of riding session. Over the whole 45 minute riding session average METs were $4.6 \pm 0.9$, RPE was 13 \pm 2 and energy expenditure was $241 \pm 73 \mathrm{kcal}$. There were no significant correlations between age, body mass, $\%$ body fat, riding frequency or fitness and oxygen cost, with the exception of BMI and \% body fat which were positively related to the oxygen cost of work without stirrups $(\mathrm{r}=0.688, \mathrm{P}=0.009$ and $\mathrm{r}=0.662, \mathrm{P}=0.009$ respectively).

\section{Discussion}


The purpose of this study was to characterize the physiological demands of different activities during a recreational horse-riding session, and to ascertain whether the intensity could be classed as at least moderate. In a group of female riders the average MET value was 5.0 for walking combined with trotting, 5.3 for trotting combined with cantering, and 4.2 for riding without stirrups. These recreational horse riding activities therefore conform to the classification for moderate intensity activity (3-6 METs), and may contribute to health-related physical activity benefits. ${ }^{2,6}$ Mean $\% \mathrm{VO}_{2 \text { peak }}$ for the different riding activities exceeded the $40 \% \mathrm{VO}_{2 \max }$ threshold commonly used as the lower threshold to define moderate exercise, while perception of effort was within or higher than the associated RPE range of 11-13. Trotting/cantering induced a significantly higher metabolic cost than exercising without stirrups, but did not classify as vigorous exercise ( $>6$ METs), and was lower than the 5.8 and 7.3 METs for trotting and cantering/galloping respectively reported in the updated Compendium of Physical Activities. ${ }^{5,14}$ None of the riding activities performed by our recreational female riders reached the Compendium's 5.5 METs for general horse riding, derived by averaging the METs for walking (3.8), trotting (5.8) and cantering/galloping (7.3), based on data collected several decades ago from male soldiers and Guatemalan agricultural workers ${ }^{15,16}$, and more recently in 5 competitive riders of whom 3 were female. ${ }^{17}$

The latter study by Devienne and Guezenne (2000) measured energy expenditure during dressage and jumping activities, and reported METs of 3 for walking, 7 for trotting, 9 for cantering and 11 for jumping. ${ }^{17}$ Averaging the walking and trotting values gives 5 METs, which matches the walk/trot METs in our study. It is also interesting that trotting elicited an intensity of $48 \pm 14 \% \mathrm{VO}_{2 \max }$ in the competitive dressage riders, matching the $48 \pm 13 \% \mathrm{VO}_{2 \text { peak }}$ for the walk/trot section in our study. The reason for the matching intensities in terms of $\% \mathrm{VO}_{2 \max }$ despite the higher absolute energy cost in Devienne and Guezenne's study is that their riders were more aerobically trained, with average $\mathrm{VO}_{2 \max }$ 
Oxygen cost of recreational horse-riding

values of $55 \mathrm{ml} \cdot \mathrm{kg}^{-1} \cdot \mathrm{min}^{-1}$ compared with $37 \mathrm{ml} \cdot \mathrm{kg}^{-1} \cdot \mathrm{min}^{-1} \mathrm{VO}_{2 \text { peak }}$ in our riders. Nevertheless, our riders were fitter than average, with $\mathrm{VO}_{2 \text { peak }}$ values $19 \%$ higher than predicted, and all but one were categorised as active or very active. In both studies there is a high degree of variability in exercise intensity among riders for the same activity, both in terms of METS and $\% \mathrm{VO}_{2 \max }$. For example, the standard deviation around the mean METs was \pm 1.5 for walking/trotting in our study and trotting in their study. This variability is higher than in other studies measuring the metabolic cost of household, garden and recreational activities in older individuals, for example sweeping (4.1 $\pm 0.7 \mathrm{METs})$, lawnmowing $(5 \pm 0.7 \mathrm{METs})$ and golfing $(2.8 \pm 0.5 \mathrm{METs}){ }^{7,31}$

Individual differences in the oxygen cost of movement can be explained by factors including age, body mass, environmental conditions, fitness or mechanical efficiency. Differences in riding experience, technique, and motivation towards the task may also contribute to the inter-individual differences for the same riding activity. In experienced and elite riders, the reported oxygen cost of trotting and cantering is approximately $70 \%$ higher than in our group of recreational riders. ${ }^{21,22}$ We did not detect any differences in physiological demand between novice and experienced riders, nor was age or fitness related to the oxygen cost of different activities. Higher body mass and percentage of body fat were positively related to oxygen cost, but only during work without stirrups.

Participants expended on average $241 \pm 73 \mathrm{kcal}$ during the 45 min session combining different riding activities, which they confirmed was representative of a typical ride for them, suggesting that they would have to repeat this 3-5 times per week to achieve the recommended 800-1200 kcal weekly energy expenditure. ${ }^{2} \quad$ Nevertheless, a 14 week intervention, during which similar horse-riding activities were performed 5 days per week, did not significantly improve health and physical fitness in similar sample of females. ${ }^{25}$ The authors recommended that riding activity needs to be supplemented 
1

3

4

5

6

7248

8

9249

10

11

$12^{250}$

13

14251

15

16252

17

18

$19^{253}$

20

21254

22

23255

25

26256

27

28257

29

30258

32

33259

34

35260

36

37

$38^{261}$

39

40262 41

${ }^{42} 263$

43

44

$45^{264}$

46

47265

48

49266

50

5

52267

53

54268

55

56

$57^{269}$

58

59

60

Oxygen cost of recreational horse-riding

with alternative aerobic and load-bearing training in this population. The British Horse Society survey showed that recreational riders also participate in associated horse-care activities such as mucking out and grooming, which may also contribute to health-related energy expenditure and fitness improvements. In a recent field study, we measured ambulatory $\mathrm{VO}_{2}$ in 8 females (18-47 yrs) during manure removal from a grazing paddock, mucking out a stable and grooming a horse (Beale et al, unpublished data). Physiological responses were similar for manure removal $(4.9 \pm 1.0$ METs, $65 \pm$ $6 \%$ predicted maximal heart rate, RPE $11 \pm 1)$ and mucking out $(4.6 \pm 1.2$ METs, $67 \pm 5 \%$ predicted maximal heart rate, RPE $12 \pm 1)$, and lower for grooming ( $3.7 \pm 0.9$ METs, $65 \pm 9 \%$ predicted maximal heart rate, RPE $9 \pm 1$ ). These data suggest that the additional activities associated with recreational horse riding are also of sufficient intensity to contribute to the achievement of the physical activity recommendations in females. However, further studies are needed to more fully characterise horseriding as a recreational activity, exploring the physiological demands of habitual riding and horse-care activities in terms of type, frequency and duration, followed by a training study to confirm whether this translates into physiological health benefits. Recreational off-road vehicle riding has recently been examined from this perspective. ${ }^{32,33}$

The limitations of the current study are that the sample size is small and consists only of females, although this does reflect statistical evidence that the large majority of recreational horse-riders are women. However, the majority of our participants were younger than the over 45 yr old group that constitutes half of all recreational riders. MET values were based on the premise that 1 MET is equivalent to $3.5 \mathrm{ml} \mathrm{O} 2 \cdot \mathrm{kg}^{-1} \cdot \mathrm{min}^{-1}$ in all individuals, a concept that has been challenged as overestimating the oxygen cost at rest. ${ }^{34}$ Data collection was limited to a structured riding session in an indoor riding school, which may not reflect the oxygen cost and energy expenditure during typical recreational riding activities. 


\section{Conclusion}

$\begin{array}{ll}7 & 272\end{array}$

8

9273 10

\section{Acknowledgements}

We are grateful to Alex Kaley for her organisation of the data collection at the Equestrian Centre, and

to the staff, students and horses who participated in this study.

\section{Funding Source}

The study was funded by the British Horse Society

This study provides novel data on the physical demand of different recreational horse riding activities in females, and indicates that these activities meet the criteria for moderate intensity physical activity and may therefore contribute to public health guidelines. Future directions from this exploratory investigation would be to determine whether a period of regular horse-riding results in improvements in physical fitness, psychological well-being and quality of life indices. 
1. World Health Organisation. Global recommendations on physical activity for health; 2010.

2. O'Donovan G, Blazevich AJ, Boreham $\mathrm{C}$, et al. The ABC of Physical Activity for Health: a consensus statement from the British Association of Sport and Exercise Sciences. J Sports Sci. 2010 28(6):573-91.

3. Department of Health. Physical Activity Guidelines in the UK: Review and Recommendations. London: Department of Health; 2010.

4. Borg G. Psychophysical bases of perceived exertion. Med Sci Sports Exerc. 1982;14(5):377-81.

5. Ainsworth BE, Haskell WL, Whitt MC, et al. Compendium of physical activities: an update of activity codes and MET intensities. Med Sci Sports Exerc. 2000 Sep;32(9 Suppl):S498-504.

6. Norton K, Norton L, Sadgrove D. Position statement on physical activity and exercise intensity terminology. J Sci Med Sport. 2010 Sep;13(5):496-502.

7. Dear JB, Porter MM, Ready AE. Energy expenditure during golfing and lawn mowing in older adult men. J Aging Phys Act. 2010;18(2):185-200.

8 Willems M, Bond T. Comparison of Physiological and Metabolic Responses to Playing Nintendo Wii Sports and Brisk Treadmill Walking. Journal of Human Kinetics. 2009;22:43-9.

9. Pretty J, Peacock J, Hine R, Sellens M, South N, Griffin M. Green exercise in the UK countryside: Effects on health and psychological well-being, and implications for policy and planning. Journal of Environmental Planning and Management. 2007;50(2):211-31.

10. Burgon H. Case studies of adults receiving horse-riding therapy. Anthrozoos: A Multidisciplinary Journal of The Interactions of People \& Animals. 2003;16(3):263-76.

11. The British Horse Society. The health benefits of horse riding in the UK; 2011.

12. The Information Centre for Health and Social Care. Health Survey for England 2008. Leeds, UK; 2008. 
Oxygen cost of recreational horse-riding

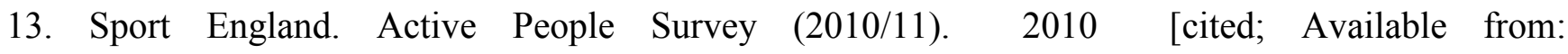

http://www.sportengland.org/research/active people survey/aps5.aspx

14. Ainsworth B, WL H, SD H, et al. Compendium of Physical Activities: a second update of codes and MET values. Med Sci Sports Exerc. 2011;43(8):1575-81.

15. Passmore A, Durnin J. Human Energy Expenditure. Phys Rev. 1955;35(4):801-40.

16. Viteri FE, Torún B, Galicia JC, Herrera E. Determining energy costs of agricultural activities by respirometer and energy balance techniques. Am J Clin Nut. 1971;24(12):1418-30.

17. Devienne MF, Guezennec CY. Energy expenditure of horse riding. Eur J Appl Physiol. 2000;82(56):499-503.

18. Meyer T, Davison RCR, Kindermann W. Ambulatory gas exchange measurements - Current status and future options. Int J Sports Med. 2005;26:S19-S27.

19. Leonard WR. Laboratory and field methods for measuring human energy expenditure. Am J Hum Biol. 2012;24(3):372-84.

20. Graves LE, Ridgers ND, Stratton G. The contribution of upper limb and total body movement to adolescents' energy expenditure whilst playing Nintendo Wii. Eur J Appl Physiol. 2008;104(4):617-23.

21. Roberts M, Shearman J, Marlin D. A comparison of the metabolic cost of the three phases of the one-day event in female collegiate riders. Comparative Exercise Physiology. 2009;6:129-35.

22. Westerling D. A study of physical demands in riding. Eur J Appl Physiol Occup Physiol. $1983 ; 50(3): 373-82$.

23. Kubota M, Nagasaki M, Tokudome M, Shinomiya Y, Ozawa T, Sato Y. Mechanical horseback riding improves insulin sensitivity in elder diabetic patients. Diabetes Res Clin Pract. 2006 Feb;71(2):124-30. 
1

24. Hosaka Y, Nagasaki M, Bajotto G, Shinomiya Y, Ozawa T, Sato Y. Effects of daily mechanical horseback riding on insulin sensitivity and resting metabolism in middle-aged type 2 diabetes mellitus patients. J Med Sci. 2010;72(3-4):129-37.

25. Meyers MC. Effect of equitation training on health and physical fitness of college females. Eur $J$ Appl Physiol. 2006;98(2):177-84.

26. Durnin JV, Womersley J. Body fat assessed from total body density and its estimation from skinfold thickness: measurements on 481 men and women aged from 16 to 72 years. $B r J$ Nutr. 1974;32(1):77-97.

27. Siri WE. Body composition from fluid spaces and density. (1961). In: Techniques For Measuring Body Composition, J. Brozek and A. Henschel (Eds.). Washington DC, USA: National Academy of Sciences National Research Council.; 1961.

28. British Association of Sport and Exercise Science. Guidelines for the physiological testing of athletes. Leeds, UK: BASES; 1997.

29. Jones NL, Makrides L, Hitchcock C, Chypchar T, McCartney N. Normal standards for an incremental progressive cycle ergometer test. Am Rev Respir Dis. 1985 May;131(5):700-8.

30. McArdle W, Katch F, Katch V. Sports \& Exercise Nutrition. Baltimore, USA. 1999.

31. Gunn SM, Brooks AG, Withers RT, Gore CJ, Plummer JL, Cormack J. The energy cost of household and garden activities in 55-to 65-year-old males. Eur J Appl Physiol. 2005;94(4):476-86.

32. Burr JF, Jamnik, VK, Shaw, JA, Gledhill, N. Physiological demands of off-road vehicle riding. Med Sci Sports Exerc. 2010 42(7): 1345-54

33. Burr JF, Jamnik, VK, Gledhill, N. Physiological fitness and health adaptations from purposeful training using off-road vehicles. Eur J Appl Physiol. 2011; 111(8):1841-50

34. Byrne N, Hills A, Hunter G, Weinsier R, Schutz Y. Metabolic equivalent: one size does not fit all. J Appl Physiol. 2005;99(3):1112-9. 
1

2359 Table 1: Horse-Riding Protocol

3

4

5

6

7

8

9

10

11

12

13

14

15

16

17

18

19360

20

21

22

23

24

25

26

27

28

29

30

31

32

33

34

35

36

37

38

39

40

41

42

43

44

45

46

47

48

49

50

51

52

53

54

55

56

57

58

59

60

\begin{tabular}{ll}
\hline Time & Activity \\
\hline $0-5 \mathrm{~min}$ & Walk warm up \\
$5-15 \mathrm{~min}$ & Walk and trot \\
$15-25 \mathrm{~min}$ & Trot and canter work \\
$25-35 \mathrm{~min}$ & Work without stirrups - sitting \\
$35-45 \mathrm{~min}$ & Cool down \\
\hline
\end{tabular}


2361 Table 2. Descriptive characteristics of participants ( $\mathrm{n}=16$, female)

\begin{tabular}{lll}
\hline Variable & Mean \pm SD & Range
\end{tabular}

\begin{tabular}{lll}
\hline Age $(\mathrm{yr})$ & $25 \pm 11$ & $17-54$ \\
Height $(\mathrm{m})$ & $1.63 \pm 0.05$ & $1.51-1.74$ \\
Weight $(\mathrm{kg})$ & $66.2 \pm 17.1$ & $45.1-109.0$ \\
$\mathrm{BMI}\left(\mathrm{kg} \cdot \mathrm{m}^{2}\right)$ & $24.7 \pm 5.4$ & $17.6-37.7$ \\
Body fat $(\%)$ & $30.6 \pm 6.4$ & $20.2-44.8$ \\
$\mathrm{VO}_{2 \text { peak }}\left({\left.\mathrm{L} \cdot \mathrm{min}^{-1}\right)}_{\mathrm{VO}_{2 \text { peak }}\left(\mathrm{ml}^{-1} \mathrm{~kg}^{-1} \cdot \mathrm{min}^{-1}\right)}^{2.407 \pm 0.519}\right.$ & $1.741-3.459$ \\
$\mathrm{VO}_{2 \text { peak }}$ as \% predicted value & $37.2 \pm 7.4$ & $29.1-56.8$
\end{tabular}


6

7

8

9367

10

11

$12^{368}$

13

14369

15

16370

17

18

19371

20

21372

22

23373

25

26374

27

28375

29

30376

32

33377

34

35378

36379

$37^{3}$

38

39

40

41

42

43

44

45

46

47

48

49

50

51

52

53

54

55

56

57

58

59

60

Oxygen cost of recreational horse-riding

Table 3: Mean $\pm \mathrm{SD}$ values for absolute and relative oxygen consumption $\left(\mathrm{VO}_{2}\right)$, percentage of peak

oxygen consumption $\left(\% \mathrm{VO}_{2 \text { peak }}\right)$, metabolic equivalent (MET), energy expenditure (EE) and RPE during the different types of riding.

walk/trot trot/canter no stirrups

5-15 $\min \quad 25-35 \mathrm{~min}$

$\begin{array}{llll}\mathrm{VO}_{2}\left(\mathrm{~L} \cdot \mathrm{min}^{-1}\right) & 1.122 \pm 0.287 & 1.240 \pm 0.430^{*} & 0.999 \pm 0.499 \\ \mathrm{VO}_{2}\left(\mathrm{ml} \cdot \mathrm{kg}^{-1} \cdot \mathrm{min}^{-1}\right) & 17.4 \pm 5.1 & 18.4 \pm 3.9^{*} & 14.5 \pm 2.9 \\ \mathrm{FVO}_{2 \text { peak }} & 48 \pm 13 & 52 \pm 12^{*} & 41 \pm 12 \\ \mathrm{MET}^{\mathrm{a}} & 5.0 \pm 1.5 & 5.3 \pm 1.1^{*} & 4.2 \pm 0.8 \\ \mathrm{EE}\left(\mathrm{kcal} . \mathrm{min}^{-1}\right) & 5.6 \pm 1.4 & 6.2 \pm 2.2^{*} & 5.0 \pm 2.2 \\ \mathrm{RPE} & 12 \pm 2 & 14 \pm 2 & 14 \pm 2\end{array}$

${ }^{\mathrm{a}}$ MET $=$ metabolic equivalent where $1 \mathrm{MET}$ is equivalent to $\mathrm{VO}_{2}=3.5 \mathrm{ml} \cdot \mathrm{kg}^{-1} \cdot \mathrm{min}^{-1}$ ${ }^{*} P<0.05$ ("trot/canter" different from "no stirrups") 
Figure 1. Mean exercise intensity expressed as metabolic equivalents (METS) averaged over each 1 minute period during the riding session. The moderate intensity exercise zone (3-6 METs) is highlighted in grey. The different activities performed are shown above the $x$-axis. $261 \times 175 \mathrm{~mm}(96 \times 96 \mathrm{DPI})$ 